\title{
Work-Life Balance: Definitions, Causes, and Consequences
}

\author{
Paula Brough, Carolyn Timms, Xi Wen Chan, Amy Hawkes, and \\ Laura Rasmussen
}

\section{Contents}

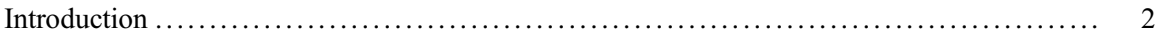

Defining Work-Life Balance ............................................ 2

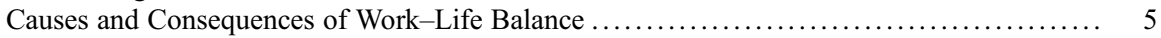

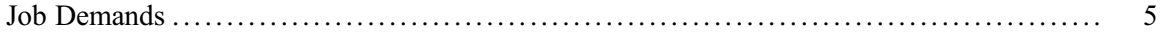

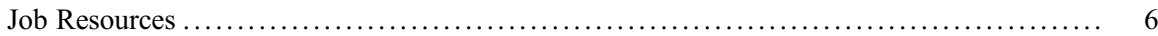

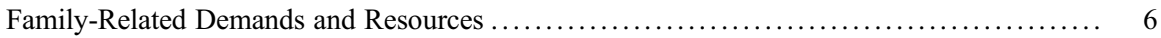

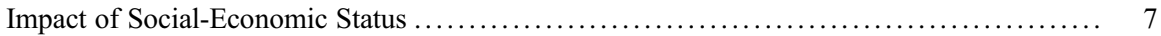

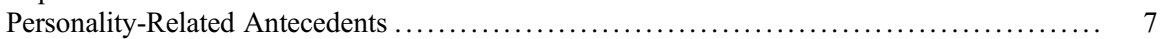

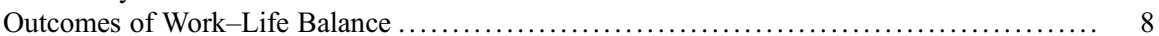

Work-Related and Family-Related Outcomes ................................. 8

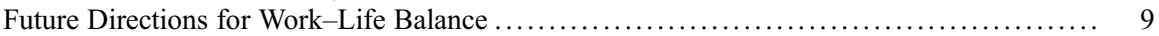

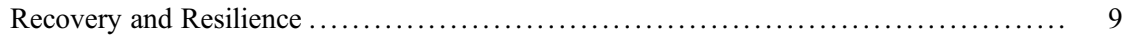

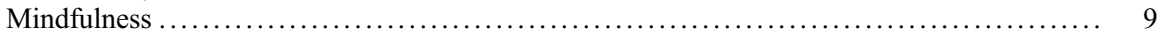

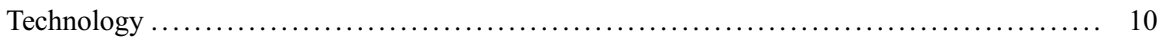

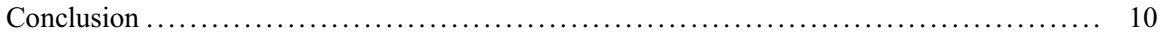

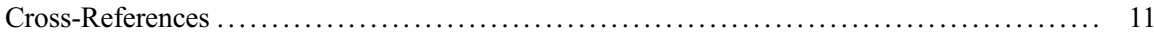

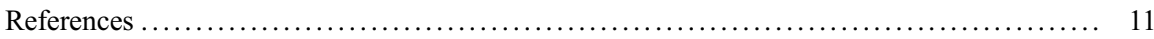

P. Brough $(\bowtie)$

School of Applied Psychology, Griffith University, Mount Gravatt, QLD, Australia

e-mail: p.brough@griffith.edu.au

C. Timms

James Cook University, Townsville, QLD, Australia

X. W. Chan

RMIT University, Melbourne, VIC, Australia

A. Hawkes · L. Rasmussen

Griffith University, Mount Gravatt, QLD, Australia

T. Theorell (ed.), Handbook of Socioeconomic Determinants of Occupational Health, Handbook Series in Occupational Health Sciences, https://doi.org/10.1007/978-3-030-05031-3_20-1 


\section{Abstract}

This chapter reviews the multiple definitions of work-life balance, including definitions focused on the equity of time spent in the work and non-work domains, satisfaction with performance/time spent in each domain, and the salience of each role for an individual. There is a general consensus that a preferred definition should focus on work-life rather than work-family, in order to include non-family responsibilities and demands, such as study or travel commitments. The chapter also discusses the common antecedents and consequences of work-life balance arising from both work and non-work domains. These include work demands and resources, family demands and resources, and personality antecedents including evidence associating psychological capital constructs with work-life balance. Finally, this chapter considers the future directions for work-life balance research, focusing on technological advancements (e.g., Fitbits) and individual levels of mindfulness and resilience. The chapter concludes by noting the increasing evidence linking employee appointments and retention with an organization's positive work-life balance culture.

\section{Keywords}

Work-life balance $\cdot$ Technology $\cdot$ Culture $\cdot$ Salience $\cdot$ Work $\cdot$ Family Satisfaction · Performance

\section{Introduction}

\section{Defining Work-Life Balance}

"Eight hours to work, Eight hours to play, Eight hours to sleep, Eight bob a day. A fair day's work, For a fair day's pay." This mantra was intoned by stonemasons who walked off their jobsite at Melbourne University in 1856. According to Franklin (2010), these skilled workers were among the first in the world to achieve an 8-hour working day. The nineteenth-century movement for a 40 -hour working week recognized the rights of humans for lives that included work, recreation, family, and recuperation and effectively preempted and sculpted the shape of the modern concept of work-life balance. Initially a simple formula in an era when the workforce was predominantly male, the concept has remained difficult to define and operationalize (Kalliath and Brough 2008a). This could largely be due to paradigms suggesting that balance was about portions of time and the domains of work, home, and social life were separate entities. Kanter (1977) challenged any notion of such separation, tendering that the different domains of workers' lives were permeable and interconnected.

Subsequently, the interface between work and people's non-work activities has been of particular interest to organizational psychologists. The interface has been described in terms of incompatibility (most commonly referred to as "conflict"; 
Carlson et al. 2000). Following a scarcity model of personal resources, the work-life interface has typically focused on how participation in multiple life roles depletes resources and produces stress and strain (Goode 1960). Alternatively, other authors have adopted a role expansion or accumulation perspective, suggesting that participation in multiple life roles can derive rewards, gratification, energy creation, and growth (Marks 1977; Sieber 1974). In this view, the interface between work and other life roles has been termed enrichment (Brough et al. 2014a; Carlson et al. 2006), enhancement (Voydanoff 2002), or facilitation (Wayne et al. 2004). In addition, societal changes precipitated by the entrance of large numbers of women into the workplace, simulating consequent changes in traditionally socially predetermined gender roles balanced against organizational imperatives for productivity gains, have also exacerbated the importance of the work-life interface (Brough et al. 2007; Lappegard et al. 2017).

Within the last 20 years, scholars have attempted to provide a more integrated view of the work-family interface, and work-life balance has been a dominant concept reflecting this perspective. However, while the term work-life balance is commonly coined, it is "a concept whose popular usage has outpaced its theoretical development" (Valcour 2007, p. 1513). Across the literature, there is still not a clear consistency in terms used to articulate the construct, and the themes that underpin conceptualizations of the construct are varied. Initial attempts to operationalize work-life balance drew upon the two primary perspectives in the extant literature, that is, role conflict and role enrichment. Within these approaches, work-life balance was commonly represented by an absence of work-family conflict coupled with high levels of work-family enrichment (Duxbury and Higgins 2001; O'Driscoll et al. 2006).

Other early conceptualizations of work-life balance focused on the notion of equal distribution of resources across work and family or other life roles. Following this approach, Kirchmeyer (2000) suggested that balance is achieved when an individual's time, energy, and commitment are evenly distributed across life roles. Meanwhile, Marks and MacDermid (1996) defined role balance as being fully engaged across all life roles. Greenhaus et al. (2003) also progressed the equality approach, suggesting that work-life balance is "the extent to which an individual is engaged in and equally satisfied with his or her work role and family role" (p. 513). Components of this definition include equal time, involvement, and satisfaction across an individual's work and non-work roles.

The equality approach, however, has received criticism, with researchers suggesting that it fails to account for an individual's role preferences or their subjective sense of balance (Brough et al. 2007). For example, Kalliath and Brough (2008b) described balance as the extent to which investment in roles is consistent with the importance or salience an individual places on a role. Similarly, work-life balance has been described as the extent to which an individual's needs for autonomy, competence, and connection with others are met. While, Voydanoff (2002) focused on the fit with available resources, suggesting that work-life balance is achieved when personal resources are adequate to meet demands in work and family roles, thereby enabling effective participation in each domain. 
As with the salience perspective, other authors have described work-life balance as a psychological construct with a focus on satisfaction across multiple roles (Kalliath and Brough 2008a). Valcour (2007) suggested that satisfaction with work-life balance is "an overall level of contentment resulting from an assessment of one's degree of success at meeting work and family role demands" (p. 1512). Valcour (2007) operationalized work-life balance via both affective (contentment) and cognitive (assessment of success) components. Similarly, Kirchmeyer (2000) defined work-life balance as "achieving satisfying experiences in all life domains and to do so requires personal resources such as energy, time, and commitment to be well distributed across domains" (p. 80).

Grzywacz and Carlson (2007) suggested that a conceptualization of work-life balance should consider the impact of an individual's balance, or lack of balance, on their work and family environments. They defined work-life balance as the "accomplishment of role-related expectations that are negotiated and shared between an individual and his/her role-related partners in the work and family domains" (p. 66). In this context, work-life balance is operationalized by individuals' perceptions of whether expectations are met that are shared and agreed with their work and family role partners. As such, it shifts the concept of work-life balance from psychological constructs (e.g., satisfaction, salience), to a focus on role-related performance.

Some authors have rejected the concept of "balance" based on the inherent implication that equal time be split between multiple roles. Halpern and Murphy (2005) likened the concept of "balance" to a balancing beam, with work and family roles on either side of a fulcrum, where time spent in one role will always negatively impact the other role. In this way, work-life balance could be seen as an unrealistic expectation. Alternatively, terms such as work-life integration or work-life harmony have been employed, to reflect a more holistic appraisal of this concept (Greenhaus and Allen 2011). Timms et al. (2015a) portrayed work-life balance in terms of complementarity, rather than compatibility of domains, suggesting that the experience of multiple roles can enhance an individual's overall sense of well-being. For example, Gini (1998) viewed work as providing a valuable sense of identity necessary within modern society and noted the grief inherent in the loss of this identity associated with job loss or retirement. Similarly, May et al. (2004) observed that work contributes a sense of personal worth and individual well-being, thereby contributing to human thriving. This is consistent with Carlson et al.'s (2006) construct of enrichment, where positive experiences in each domain of people's lives improve and enhance the quality of life in the other domains.

Allen (2013) employed the term work-family balance but applied it to the multiple domains of individuals' lives. Other researchers (e.g., Kalliath and Brough 2008b; Keeney et al. 2013) have asserted that the term work-life balance is more inclusive of those employees who are not parents but who nevertheless wish to accommodate interests such as study, sports, religious observance, and travel with their work commitments. A recent refinement by Casper et al. (2018) suggested that this concept could be more accurately stated as work-non-work balance. They accentuated employees' assessment of how personally favorable the combination of work and non-work roles was for them. This has resonance with Brough et al. 
(Brough et al. 2014b) observation that people could experience substantial time commitments at work that did not necessarily interfere with their subjective sense of balance between the domains of their lives. Casper et al. (2018) identified three subjective balance domains previously not acknowledged by researchers: affect (emotional), effectiveness (sense of success), and involvement (level of engagement) as instrumental in contributing to individuals' sense of balance between their work and non-work domains. In this chapter, the term work-life balance is employed, while acknowledging the variations in the published definitions of this construct.

\section{Causes and Consequences of Work-Life Balance}

Since Kalliath and Brough's (2008b) call for systematic reviews of the antecedents, moderators, mediators, and consequences of work-life balance, there has been a proliferation of studies focusing on the antecedents and outcomes of work-life balance. A summary and synthesis of these key antecedents and outcomes are provided below. First, the evidence associated with three types of antecedents of work-life balance, (a) work-related, (b) family-related, and (c) other non-workrelated, is reviewed.

\section{Job Demands}

A majority of the research on work-life balance has focused on its work-related antecedents. These studies primarily draw on resource-based theories (viz., job demands-resources, conservation of resources, work-home resources model, and resource-gain-development perspective) to explain the impact of work-related demands and resources upon work-life balance. Job demands are the physical, psychological, social, or organizational aspects of the job requiring constant physical and psychological effort. Job demands are commonly defined as time-based demands (e.g., overtime and nonstandard work schedules), strain-based or cognitive demands (e.g., task difficulty and mental load), affect-based or emotional demands (e.g., negative mood and leader or co-worker hostility), or physical demands (e.g., manual jobs that require intense labor; Brough and Biggs 2015). Evidence indicates that job demands generally have a negative influence on work-life balance. For example, both Brough et al. (2014b) and Haar et al. (2018) found that cognitive job demands decreased employees' perceptions of their work-life balance, while Syrek et al. (2013) demonstrated that time pressures reduced work-life balance. Job demands reduce perceptions of work-life balance primarily due to the effort exerted to meet these job demands, which subsequently hinders an individual's efforts to fulfill their responsibilities within their non-work domains.

However, some research has indicated that specific job demands can actually enhance levels of work-life balance. For example, LePine et al. (2005) distinguished between challenge demands and hindrance demands, suggesting that challenging job demands may have the potential to promote personal gain or growth, positive 
emotions, and an active style of coping. Similarly, Green and Skinner (2005) found that amidst the increased workloads, longer working hours, and greater time pressures, some employees have learnt to work "smarter" through experience and time management training to achieve an acceptable level of work-life balance.

\section{Job Resources}

Job resources are the physical, psychological, social, or organizational aspects of the job that facilitate the achievement of work goals. In general, employees strive to protect their current resources and acquire new resources, which enable them to cope with their job demands (Halbesleben et al. 2014). Similar to job demands, job resources are also categorized as time-based resources (e.g., job flexibility and alternative work schedules), cognitive resources (e.g., mental resilience and attention), emotional resources (e.g., mood and optimism), or physical resources (e.g., strength and skills). Evidence is consistent that job resources have a positive impact on work-life balance. For example, Hill et al. (2001) found that job flexibility in terms of timing (flextime) and work location (flexiplace) generated a positive spillover effect from work to home, helping employees to achieve work-life balance. Similarly, Ferguson et al. (2012) demonstrated that both co-worker and partner support reinforced positive experiences facilitating work-life balance. Finally, both Greenhaus et al. (2012) and Brough et al. (2005) also showed that having a supervisor who was supportive of an employee's family demands was positively related to the employee's levels of work-life balance.

\section{Family-Related Demands and Resources}

Less attention has been focused on the family-related antecedents of work-life balance. The associations between family-related antecedents and work-life balance are generally weaker than compared to the associations between work-related antecedents and work-life balance. Alongside partner support (Ferguson et al. 2012), other specific family resources demonstrating an influence for work-life balance include family support (Russo et al. 2016), family-to-work enrichment (Chan et al. 2016), spending quality time with children (Milkie et al. 2010), partner's work-life balance satisfaction (Stock et al. 2014), and home-based business (Walker et al. 2008). Interestingly, these family resources have been found to benefit female employees more than male employees. Family demands which have been examined in relation to work-life balance include family involvement (Aryee et al. 2005; Stock et al. 2014) and caring for children and/or aging parents and relatives (Brough and O'Driscoll 2005; Neal and Hammer 2017). Family demands predominately affect employees juggling both work and family commitments and generally hinder an individual's ability to achieve their desired level of work-life balance (Chan et al. 2017). 


\section{Impact of Social-Economic Status}

Education is the most robust predictor of the quality of work people can perform. Lower educational attainment is associated with lower economic status and menial (and therefore, less flexible) work. According to Montez et al. (2014), workers with the least choice of flexibility in their work are single parents (predominately single mothers) with only a rudimentary education. These workers experience high levels of work-family conflict and insecurity due to severe competing demands on their time and consequently experience lower health outcomes. Stack and Meredith (2018) reported that single working parents experienced grinding poverty, psychological distress, and anxiety, even when employed on a full-time basis, because of their low hourly rates of pay. According to Danziger and Waters Booth (2008), although the non-work needs of low SES workers echo those of higher SES workers, they are less likely to be accommodated by employers due to the casual nature of the work. With regard to specific Australian experiences, Carney and Stanford (2018) reported that insecurities facing low SES workers include reducing wages, increasing casualization of the workforce, underemployment, and indifferent protection by such mechanisms as enterprise agreements. Similarly, the Australian Institute of Health and Welfare (2019) reported that while 30\% of Australians work part time, $9 \%$ of employed people are underemployed. This reveals that although part-time work constitutes flexibility for some workers, for others it represents insecurity and a reduction in living standards.

\section{Personality-Related Antecedents}

Aryee et al. (2005) found weak associations between proactive personality characteristics and work-life balance, and between neuroticism and work-life balance, and suggested that personality variables are more strongly related to work-family enrichment than to work-life balance. Kossek and Lautsch (2012) described work-family boundary management style as a personality-related antecedent of work-life balance, which refers to how an individual demarcates their work and family boundaries and roles. Boundary management styles include segmentation, integration, and alternating. In general, segmentation (delineating work and personal life as separate domains) facilitates work-life balance, integration (delineating work and personal life as freely interacting domains) reduces levels of work-life balance, while alternating (clear periods of segmentation and integration) facilitates work-life balance in the long term (Kossek and Lautsch 2012; Matthews et al. 2010).

Psychological capital (PsyCap) comprising self-efficacy, optimism, hope, and resiliency has generally been demonstrated to have a positive influence on levels of work-life balance. Drawing on Hobfoll's (1988) conservation of resources (COR) theory, specifically the tenet that people strive to retain, protect, and build resources, Siu (2013) demonstrated that the four components of PsyCap each significantly enhanced individuals' work-life balance over time. Similarly, Chan et al. (2016) also 
found that domain-specific self-efficacy (self-efficacy to regulate work and life) facilitated employees' achievement of work-life balance, as they were more likely to believe in their own ability to maintain a balance between work and non-work demands.

\section{Outcomes of Work-Life Balance}

\section{Work-Related and Family-Related Outcomes}

Research on work-life balance has primarily focused on its work-related outcomes, which primarily consist of job satisfaction, turnover, turnover intentions, work engagement, organizational citizenship behavior, job performance, job involvement, and career outcomes. Less attention has been given to the family-related outcomes of work-life balance which primarily include family satisfaction, family functioning, and family performance. For example, evidence of significant associations over time between work-life balance and both job satisfaction and family satisfaction have been demonstrated with samples of workers drawn from numerous national cultures (e.g., O’Driscoll et al. 2004; Spector et al. 2007). Evidence also suggests that work-life balance also mediates the associations between job stress and adverse mental health outcomes (e.g., depression and anxiety) for workers (e.g., Timms et al. 2015b). Similarly, Chan et al. (2017) demonstrated that work-life balance mediated the associations between both work and family demands and an employee's perception of work engagement. Chan et al. (2017) noted that the relationships between work demands and work engagement were stronger, compared to the family demands and work engagement pathways. Furthermore, the mediation of family demands and work engagement by work-life balance was reduced to non-significance when an employee's level of self-efficacy was controlled. Chan et al. (2017) concluded that "when prioritising work responsibilities, employees [still] sacrifice their family and personal roles in the process" (p. 830). Importantly, it appears that an employee's personal characteristics, including their levels of self-efficacy, appear to influence work-life balance outcomes to a similar or even greater extent than family demands directly.

Overall, when employees perceive themselves as having an acceptable level of work-life balance, they experience positive work-related outcomes due to the accumulation of resources, increase in self-beliefs to achieve goals, positive spillover of resources from the non-work to work domain, and reciprocity of favorable treatment to the organization. Sometimes, work-life balance may not directly impact work outcomes but instead may facilitate the accumulation of resources such as affective commitment (Kim 2014) which in turn does enhance work outcomes such as job performance. Importantly, the evidence has established that both formal and informal access to appropriate organizational work-life balance policies clearly assists employees to manage their multiple role demands (Brough and O'Driscoll 2010). Consequently, these employees have positive work attitudes and performance levels. Conversely, not having appropriate access to organizational work-life 
balance policies, or having an organizational culture which discourages this access, is associated with negative work attitudes and performance, including employee turnover (Brough et al. 2009).

\section{Future Directions for Work-Life Balance}

\section{Recovery and Resilience}

It is apparent that work-life balance is more complex than a simple conflict between domains. As discussed at the start of this chapter, the recent focus on values, satisfaction, and experiences provides welcome depth to this field (Casper et al. 2018; Kalliath and Brough 2008b). Consistent with this shift to explore balance with life more broadly, there has been growing recognition that activities outside of work can have restorative benefits for individuals, enhancing subsequent levels of work performance (Sonnentag 2003). Employees who demonstrate appropriate "recovery" (or "resilience") from their work demands are more engaged, have higher job performance, and display more organizational citizenship behaviors (Binnewies et al. 2010). These benefits have been found when recovery is achieved in the evening, over weekends, or while on vacation (Fritz et al. 2010). It is proposed that such recovery enables resources to be replenished, thereby enabling employees to cope better with subsequent job demands.

An inherent risk when discussing recovery is that blame for burnout and strain falls solely on the individual for not managing to appropriately recover outside of work. However, it is apparent that appropriate provisions of organizational support and work-life balance policies, including the provision of an organizational culture encouraging work-life balance and recovery techniques, do reduce employees' experiences of psychological strain and burnout (e.g., Brough et al. 2009). Furthermore, it is likely that the recovery from the demands of family/carer responsibilities is just as important as the recovery from work demands. Further research is required to explain more specifically how recovery experiences impact employee outcomes beyond well-being and productivity, to include, for example, broader improvements in work-life balance (Sonnentag et al. 2016).

\section{Mindfulness}

Mindfulness has also recently been a focus of mental health research and, for example, has recently been applied as an intervention for occupational stress and well-being (e.g., Eby et al. 2017). Mindfulness is the nonjudgmental awareness of your surroundings, "being attentive to and aware of what is taking place in the present" (Brown and Ryan 2003 p. 822). Evidence indicates that mindfulness can be beneficial when employed to manage competing role demands. For example, Michel et al. (2014) trained employees to use mindfulness as a segmentation strategy aimed to reduce strain-based work-family conflict. Compared to the control group, the 
mindfulness group demonstrated significant reductions in conflict and significant increases in psychological detachment. Trait mindfulness has also been found to improve sleep quality and vitality and subsequent reports of work-life balance (Allen and Kiburz 2012).

Both the application of recovery and mindfulness to the work-life balance research field emphasizes a focus on the individual employee, as was mentioned above. It is important to recognize that individually focused interventions can only succeed to a certain extent. Experiencing chronically high levels of work and/or family demands in an organization offering limited access to available work-life balance policies will produce adverse employee outcomes which are only partially offset by levels of recovery, resilience, and mindfulness.

\section{Technology}

At the broader level, there has been a rapid shift in technology use at work. These changes have provided greater flexibility and choice in where, when, and how an employee works, offering opportunities to bolster work-life balance levels (Day et al. 2010). However, this flexibility can also be problematic, with the boundaries between work and home becoming increasingly indistinct. Employees may now access emails on their smart phones immediately after waking and also work online late into the evening. Evidence suggest that the chronic practice of "constant availability" is detrimental by, for example, impinging on an employee's recovery time (Barley et al. 2011; O'Driscoll et al. 2010; Lupton 2018). Furthermore, the impact of smart devices worn on the body (e.g., iWatch, Fitbit, Garmin) has yet to be empirically assessed in relation to employee mental health and the implications for work-life balance. These devices mean that even when an employee is away from their computer or mobile phone (e.g., practicing work recovery in a gym class), they may still receive work notifications. The negative impact of technology on employee's mental health outcomes has stimulated some legislation to control its use (particularly in regard to work email), outside of work hours to assist employees to achieve deliberate segmentation of their work and non-work lives (e.g., O'Driscoll et al. 2010). It is likely that the formal control of such technology will increase in the future, occurring either at organizational policy or at national legislative levels, in order to safeguard employees' levels of work-life balance.

\section{Conclusion}

This chapter serves to update our current thinking about work-life balance. The chapter discussed the multiple definitions of work-life balance which commonly occur and acknowledged that the field has moved beyond a simple focus on work and family, to a focus which includes a variety of work and other life demands salient to an employee. This broader definition of work-life balance is consequently applicable to a larger subset of employees, rather than those simply caring for 
young children. The predominate antecedents and consequences of work-life balance which guide current research were also discussed. The focus on work/non-work demands and resources remains common. It is apparent that an abundance of chronic demands from multiple domains, coupled with inadequate levels of person and organizational resources (e.g., time, support), remains the strongest causes of conflict or imbalance. An imbalance of multiple role demands may be manageable in the short term and especially so with the use of individually focused recovery/resilience strategies, but such an imbalance rarely produces positive outcomes in the longer term. For those employees with a choice of employer, preferences are increasing for employers offering desirable organisational work-life balance polices, and who also enable access to these policies; that is, organisations with a positive work-life balance organisational culture. Finally, the recent technological developments that can lead to a state of employee permanent availability were noted, contradicting the recognized benefits of work "downtime" or recovery. Finally, it was suggested that it will become increasingly necessary for organizations to formally mandate the use of such technology within their work-life balance policies.

\section{Cross-References}

- Discrimination and Bullying at Work

- Gender Perspectives on Employment and Health

- Impact of Digitalization on Work and Employment

- Interactions of Work and Health: an Economic Perspective

$\checkmark$ Job Insecurity

$\checkmark$ Long Working Hours

- Shift Work

- Under- and Over-Employment

\section{References}

Allen T (2013) The work-family interface: a synthesis of research from industrial and organizational psychology. In: Weiner I (ed) Handbook of psychology, vol 12, 2nd edn. Wiley, Hoboken, pp 698-718

Allen TD, Kiburz KM (2012) Trait mindfulness and work-family balance among working parents: The mediating effects of vitality and sleep quality. J Vocat Behav 80(2):372-379. https://doi.org/ 10.1016/j.jvb.2011.09.002

Aryee S, Srinivas ES, Tan HH (2005) Rhythms of life: antecedents and outcomes of work-family balance in employed parents. J Appl Psychol 90(1):132-146

Australian Institute of Health and Welfare (2019) Australia's welfare 2019 in brief. Retrieved from Canberra: https:/www.aihw.gov.au/getmedia/795385cc-6493-45c9-b341-7ddf6006d518/aihwaus-227.pdf.aspx?inline $=$ true

Barley SR, Meyerson DE, Grodal S (2011) E-mail as a source and symbol of stress. Organ Sci 22(4):887-906. https://doi.org/10.1287/orsc.1100.0573 
Binnewies C, Sonnentag S, Mojza EJ (2010) Recovery during the weekend and fluctuations in weekly job performance: a four-week longitudinal study examining intra-individual relationships. J Occup Organ Psychol 83:419-441

Brough P, Biggs A (2015) Job demands x job control interaction effects: do occupation-specific job demands increase their occurrence? Stress Health 31(2):138-149. https://doi.org/10.1002/ smi.2537

Brough P, O'Driscoll M (2005) Work-family conflict and stress. In: Antoniou A, Cooper C (eds) Research companion to organizational Health Psychology. Edward Elgar Publisher, Cheltenham, pp 346-365

Brough P, O'Driscoll M (2010) Organisational interventions for balancing work and home demands: an overview. Work \& Stress 24:280-297. https://doi.org/10.1080/ 02678373.2010.506808

Brough P, O'Driscoll M, Kalliath T (2005) The ability of 'family friendly' organisational resources to predict work-family conflict and job and family satisfaction. Stress Health 21:223-234. https://doi.org/10.1002/smi.1059

Brough P, O'Driscoll MP, Kalliath TJ (2007) Work-family conflict and facilitation: achieving workfamily balance. In: Glendon AI, Thompson BM, Myors B (ed) Advances in organisational psychology. Australian Academic Press, Brisbane. 73-92

Brough P, O'Driscoll MP, Biggs A (2009) Parental leave and work-family balance among employed parents following childbirth: an exploratory investigation in Australia and New Zealand. Kotuitui: N Z J Soc Sci Online 4:71-87. https://doi.org/10.1080/1177083X.2009.9522445

Brough P, Hassan Z, O’Driscoll MP (2014a) Work life enrichment. In: Dollard M, Shimazu A, Bin Nordin R, Brough P, Tuckey M (eds) Psychosocial factors at work in the Asia Pacific. Springer, London, pp 323-336

Brough P, Timms C, O'Driscoll MP, Kalliath T, Siu OL, Sit C, Lo D (2014b) Work-life balance: a longitudinal evaluation of a new measure across Australia and New Zealand workers. Int J Hum Resour Manag 25(19):2724-2744

Brown KW, Ryan RM (2003) The benefits of being present: mindfulness and its role in psychological Well-being. J Pers Soc Psychol 84(4):822-848. https://doi.org/10.1037/00223514.84.4.822

Carlson DS, Kacmar K, Williams L (2000) Construction and initial validation of a multidimensional measure of work/family conflict. J Vocat Behav 56(2):249-276

Carlson DS, Kacmar KM, Wayne JH, Grzywacz JG (2006) Measuring the positive side of the workfamily interface: development and validation of a work-family enrichment scale. J Vocat Behav 68(1):131-164. https://doi.org/10.1016/j.jvb.2005.02.002

Carney T, Stanford J (2018) The dimensions of insecure work: a Factbook. Retrieved from Canberra: https://www.tai.org.au/sites/default/files/Insecure_Work_Factbook.pdf

Casper WJ, Vasziri H, Wayne J, DeHauw S, Greenhaus J (2018) The jingle-jangle of work-nonwork balance: a comprehensive and meta-analytic review of its meaning and measurement. J Appl Psychol 103(2):182-214

Chan XW, Kalliath T, Brough P, Siu OL, O’Driscoll MP, Timms C (2016) Work-family enrichment and satisfaction: the mediating role of self-efficacy and work-life balance. Int J Hum Resour Manag 27(15):1755-1776

Chan XW, Kalliath T, Brough P, O’Driscoll M, Siu OL, Timms C (2017) Self-efficacy and work engagement: test of a chain model. Int J Manpow 38(6):819-834

Danziger A, Waters Booth S (2008) Lower-wage workers and flexible work arrangements. Retrieved from Washington D.C. https://scholarship.law.georgetown.edu/cgi/viewcontent.cgi? article $=1000 \&$ context $=$ legal

Day A, Scott N, Kelloway KE (2010) Information and communication technology: Implications for job stress and employee well-being. In: New developments in theoretical and conceptual approaches to job stress. Emerald Group Publishing Limited, Bingley, pp 317-350

Duxbury L, Higgins C (2001) Work-life balance in the new millennium: Where are we? Where do we need to go? CPRN, Ottawa 
Eby LT, Allen TD, Conley KM, Williamson RL, Henderson TG, Mancini VS (2017) Mindfulnessbased training interventions for employees: a qualitative review of the literature. Hum Res Manage Rev. https://doi.org/10.1016/j.hrmr.2017.03.004

Ferguson M, Carlson D, Zivnuska S, Whitten D (2012) Support at work and home: the path to satisfaction through balance. J Vocat Behav 80(2):299-307

Franklin N (writer). (2010) The rise and fall of the 8 hour day: part one. In Raynor M (producer), Hindsight. Australian Broadcasting commission, Melbourne

Fritz C, Sonnentag S, Spector PE, McInroe JA (2010) The weekend matters: relationships between stress recovery and affective experiences. J Organ Behav 31(8):1137-1162. https://doi.org/ $10.1002 /$ job. 672

Gini A (1998) Work, identity and self: how we are formed by the work we do. J Bus Ethics 17(7):707-714

Goode WJ (1960) A theory of role strain. Am Psychol Rev 25:483-496

Green P, Skinner D (2005) Does time management training work? An evaluation. Int J Train Dev 9(2):124-139

Greenhaus JH, Allen TD (2011) Work-family balance: a review and extension of the literature. In: Handbook of occupational Health Psychology, 2nd edn. American Psychological Association, Washington, DC, pp 165-183

Greenhaus JH, Collins KM, Shaw JD (2003) The relation between work-family balance and quality of life. J Vocat Behav 63(3):510-531

Greenhaus JH, Ziegert JC, Allen TD (2012) When family-supportive supervision matters: relations between multiple sources of support and work-family balance. J Vocat Behav 80(2):266-275

Grzywacz JG, Carlson DS (2007) Conceptualizing work - family balance: Implications for practice and research. Adv Dev Hum Res 9(4):455-471

Haar JM, Sune A, Russo M, Ollier-Malaterre A (2018) A cross-national study on the antecedents of work-life balance from the fit and balance perspective. Social Indicators Research.:Advance online publication. https://doi.org/10.1007/s11205-018-1875-6

Halbesleben JR, Neveu JP, Paustian-Underdahl SC, Westman M (2014) Getting to the "COR" understanding the role of resources in conservation of resources theory. J Manag 40(5):1334-1364

Halpern DF, Murphy SE (2005) From work-family balance to work-family interaction: changing the metaphor. Erlbaum Publishers, Mahwah

Hill EJ, Hawkins AJ, Ferris M, Weitzman M (2001) Finding an extra day a week: the positive influence of perceived job flexibility on work and family life balance. Fam Relat 50(1):49-58

Hobfoll SE (1988) The ecology of stress. Hemisphere, New York

Kalliath T, Brough P (2008a) Work-life balance: a review of the meaning of the balance construct. J Manag Organ 14(3):323-327

Kalliath T, Brough P (2008b) Achieving work-life balance. J Manage Org 14(3):224-226

Kanter RM (1977) Work and family in the United States: a critical review and agenda for research and policy. Russell Sage Foundation, New York

Keeney J, Boyd E, Sinha R, Westring A, Ryan A (2013) From "work-family" to "work-life": broadening our conceptualization and measurement. J Vocat Behav 82(3):221-237

Kim HK (2014) Work-life balance and employees' performance: the mediating role of affective commitment. Glob Bus Manag Res 6(1):37-51

Kirchmeyer C (2000) Work-life initiatives: greed or benevolence regarding workers' time? In: Cooper CL, Rousseau DM (eds) Trends in organizational behavior: time in organizational behavior, vol 7. Wiley, Chichester, pp 79-94

Kossek EE, Lautsch BA (2012) Work-family boundary management styles in organizations: a cross-level model. Organ Psychol Rev 2(2):152-171

Lappegard T, Goldscheider F, Bernhardt E (2017) Introduction to the special collection on finding work-life balance: history, determinants, and consequences of new breadwinning models of the industrialized world. Demogr Res 37(26):853-865 
LePine JA, Podsakoff NP, LePine MA (2005) A meta-analytic test of the challenge stressor-hindrance stressor framework: an explanation for inconsistent relationships among stressors and performance. Acad Manag J 48(5):764-775

Lupton D (2018) Digital health. Routledge, London

Marks SR (1977) Multiple roles and role strain: some notes on human energy, time and commitment. Am Sociol Rev 42:921-936

Marks SR, MacDermid SM (1996) Multiple roles and the self: a theory of role balance. J Marriage Fam 58:417-432. https://doi.org/10.2307/353506

Matthews RA, Barnes-Farrell JL, Bulger CA (2010) Advancing measurement of work-family boundary characteristics. J Vocat Behav 77(3):447-460

May DR, Gilson RL, Harter LM (2004) The psychological conditions of meaningfulness, safety and availability and the engagement of the human spirit at work. J Occup Organ Psychol 77:11-37

Michel A, Bosch C, Rexroth M (2014) Mindfulness as a cognitive-emotional segmentation strategy: an intervention promoting work-life balance. J Occup Organ Psychol 87(4):733-754

Milkie MA, Kendig SM, Nomaguchi KM, Denny KE (2010) Time with children, children's Wellbeing, and work-family balance among employed parents. J Marriage Fam 72(5):1329-1343

Montez J, Sabbath E, Glymour M, Berkman L (2014) Trends in work-family context among U.S. women by education level, 1976-2011. Popul Res Policy Rev 33:629-648. https://doi.org/ 10.1007/s11113-013-9315-4

Neal MB, Hammer LB (2017) Working couples caring for children and aging parents: effects on work and Well-being. Psychology Press, New York

O'Driscoll M, Brough P, Kalliath T (2004) Work-family conflict, psychological Well-being, satisfaction and social support: a longitudinal study in New Zealand. Equal Oppor Int 23:36-56. https://doi.org/10.1108/02610150410787846

O'Driscoll M, Brough P, Kalliath T (2006) Work-family conflict and facilitation. In: Jones F, Burke RJ, Westman M (eds) Work-life balance: A psychological perspective. Psychology Press, Hove, pp 117-142

O’Driscoll M, Brough P, Timms C, Sawang S (2010) Engagement with information and communication technology and psychological well-being. In: Perrewé PL, Ganster DC (eds) New developments in theoretical and conceptual approaches to job stress, vol 8. Emerald, Bingley, pp 269-316

Russo M, Shteigman A, Carmeli A (2016) Workplace and family support and work-life balance: implications for individual psychological availability and energy at work. J Posit Psychol 11(2):173-188

Sieber SD (1974) Toward a theory of role accumulation. Am Sociol Rev 39(4):567-578

Siu OL (2013) Psychological capital, work Well-being, and work-life balance among Chinese employees. J Pers Psychol 12(4):170-181

Sonnentag S (2003) Recovery, work engagement, and proactive behavior: a new look at the interface between nonwork and work. J Appl Psychol 88(3):518

Sonnentag S, Unger D, Rothe E (2016) Recovery and the work-family interface. In: Allen TD, Eby LT (eds) The Oxford handbook of work and family, vol 95. https://doi.org/10.1093/oxfordhb/ 9780199337538.013.37

Spector PE, Allen TD, Poelmans S, Lapierre LM, Cooper CL, O'Driscoll M, Sanchez JI, Abarca N, Alexandrova M, Beham B, Brough P, Ferreiro P, Fraile G, Lu C-Q, Lu L, Moreno-Velazques I, Pagon M, Pitariu H, Salamtov V, Shima S, Simoni AS, Siu OL, Widerszal-Bazyl M (2007) Cross-national differences in relationships of work demands, job satisfaction and turnover intentions with work-family conflict. Pers Psychol 60:805-835. https://oi.org/10.1111/ j.1744-6570.2007.00092.x

Stack R, Meredith A (2018) The impact of financial hardship on single parents: an exploration of the journey from social distress to seeking help. J Fam Econ Iss 39:233-242. https://doi.org/ $10.1007 / \mathrm{s} 10834-017-9551-6$ 
Stock RM, Bauer EM, Bieling GI (2014) How do top executives handle their work and family life? A taxonomy of top executives' work-family balance. Int J Hum Resour Manag 25(13):1815-1840

Syrek CJ, Apostel E, Antoni CH (2013) Stress in highly demanding IT jobs: transformational leadership moderates the impact of time pressure on exhaustion and work-life balance. J Occup Health Psychol 18(3):252-261

Timms C, Brough P, Siu OL, O'Driscoll M, Kalliath T (2015a) Cross-cultural impact of work-life balance on health and work outcomes. In: Lu L, Cooper CL (eds) Handbook of research on work-life balance in Asia. Edward Elgar Publishing, Cheltenham, pp 295-314

Timms C, Brough P, O'Driscoll M, Kalliath T, Siu O, Sit C, Lo D (2015b) Flexible work arrangements, work engagement, turnover intentions and psychological health. Asia Pac J Hum Resour 53(1):83-103

Valcour M (2007) Work-based resources as moderators of the relationship between work hours and satisfaction with work-family balance. J Appl Psychol 92:1512-1523. https://doi.org/10.1037/ 0021-9010.92.6.1512

Voydanoff P (2002) Linkages between the work-family interface and work, family, and individual outcomes: an integrative model. J Fam Issues 23(1):138-164

Walker E, Wang C, Redmond J (2008) Women and work-life balance: is home-based business ownership the solution? Equal Oppor Int 27(3):258-275

Wayne JH, Musisca N, Fleeson W (2004) Considering the role of personality in the work-family experience: relationships of the big five to work-family conflict and facilitation. J Vocat Behav 64:108-130 